\title{
TENSILE PROPERTIES OF SURFACE MODIFIED BAMBOO SLICES COATED WITH EPOXY RESIN CONSIDERING THE CORROSION OF ACID AND ALKALI ENVIRONMENT
}

\author{
Qiang Ma, Zhao Liu, Henglin Xiao, Zhi Chen \\ Hubei University Of Technology \\ CHINA
}

(Received April 2020)

\begin{abstract}
This paper presents an anticorrosive method to protect bamboo from the corrosion induced by coating a layer of epoxy resin on the surface of bamboo slices. Four surface modifications including heat treatment, alkali treatment, coupling treatment and acetylation treatment are applied to bamboo slices. The results indicate that the ultimate tension of bamboo slices decreases when corroded in solutions with different $\mathrm{pH}$ for different time, while epoxy resin protects the bamboo slices from corrosion to maintain the tensile properties by coated on its surface. The surface morphology indicates that four modifications have different degrees of influence on the surface and material of bamboo slices, which can reduce the ultimate tension of bamboo slices, but improve the interfacial combination between the surface of bamboo slices and epoxy resin. Acetylation treatment was the most effective modification analysed by Fourier-transform infrared spectroscopy (FT-IR) among them.
\end{abstract}

KEYWORDS: Bamboo slices, epoxy resin, corrosion, tensile properties, surface modifications, interfacial combination.

\section{INTRODUCTION}

With the continuous deepening of the concept of green economy and sustainable development, the application of ecological building materials, especially those used as reinforcement in construction technology for reinforced soil, has been increasingly attended. Some natural plant materials with high strength and favorable toughness, such as bamboo root, palm fiber and wheat straw, when be used as reinforcement, can effectively improve the mechanical properties of the reinforced soil (Hegde and Sitharam 2015, Li et al. 2012). Moreover, the tensile properties 
of the reinforcement are the most basic technical indicators for reinforced soil structural design, which can directly affect the mechanical properties and service life of the reinforced soil (Shinoda and Bathurst 2004, Wesseloo et al. 2004, Subaida et al. 2008). For example, slope soil maintains its slope stability when reinforced with plant roots, and the tension of plant roots plays a leading role in the stability of soil, which has been proved by the tensile test and the direct shear test on roots-reinforced soil (McIvor et al. 2008, Ghestem et al. 2011, Ma et al. 2018). Compared with some synthetic materials, natural plant materials provide better reinforcement in construction technology for reinforced soil. More importantly, they are degradable and environmentally friendly, which have better economic and ecological benefits as traditional geopolymer replacement for reinforcement engineering.

The recent progress of green building materials presents a great opportunity for the application of bamboo in the reinforced soil. As a kind of natural reinforcement, bamboo is recognized as a viable, sustainable and engineering alternative to other materials in many areas worldwide (Ahmad and Kamke 2005, Yan et al. 2017). It possesses various applications in the engineering field for its strong adaptability, regeneration and reproduction ability, and can play a better role than other natural plant material in the reinforcement process (Khalil et al. 2012, Luo et al. 2014, Trujillo et al. 2014). At present, there are many researches on the mechanical properties of bamboo and its application in practical engineering. Tensile strength of single bamboo fiber isolated chemically is $47.6 \%$ higher than that of isolated mechanically, and the tensile strength and modulus of bamboo strips made from the outer portion of the bamboo are higher than that of inner portion (Chen et al. 2015). The shear strength of soil can be improved by reinforcing with bamboo slices, and the peak shear strength of bamboo root reinforced soil increases with increasing soil-root volume ratio (Ma'ruf 2012).

However, the degradability of natural plants makes them prone to corrosion in acid and alkali environment, which may affect their mechanical properties and makes them difficult to chronically exert their reinforcing effect (Hsu et al. 2010). Notably, due to the influence of civil engineering environment, the natural bamboo material will be corroded when be applied as reinforcement in the soil (Qin et al. 2015), which will decrease the mechanical properties of the reinforced soil. Therefore, to extend the service life of bamboo and maintain the mechanical properties of reinforced soil, it is particularly important to conduct corrosion prevention on bamboo (Shafizadeh and Kavanagh 2005). The anticorrosion of bamboo mainly include physical and chemical methods. However, The validity of physical methods is short, and such as heat treatment will decrease the mechanical properties of bamboo (Yun et al. 2016, Zhao et al. 2019). Chemical method is to use preservatives to kill fungi and pests in bamboo, which will easily pollute the environment and has been pointed out that preservatives are not evenly distributed in bamboo (Qin et al. 2015). An effective and economic anti-corrosion method is to coat the material with epoxy resin, a kind of polymer with good physical properties, corrosion resistance, abrasion resistance, stability and low cost (Yang et al. 2014). However, the poor adsorbability towards polymers, induced by the hydrophilicity of nature plant, makes adhesion between the nature plant and polymer inadequate (Luft 1961, Antov et al. 2020). On the basis of maintaining the form and strength of natural plant, the surface modification of natural plant by physical or chemical methods can improve the interfacial compatibility between the surface of natural plant and epoxy resin (Bledzki et al. 1996). Although there are many research articles concerning the tensile properties of bamboo, the focus is seldom concentrated upon the bamboo corrosion that occurs during application in the recent literature. And there are few studies on the regularities of mechanical properties of bamboo slices under corrosion, the anticorrosion effect of epoxy resin on bamboo slices, and the influences of surface modification in improving the interfacial combination between epoxy resin and bamboo slices. 
To solve the above problems, in this paper, the mechanical properties of Moso bamboo slices under different $\mathrm{pH}$ and corrosion time were studied, and the anti-corrosion effect of epoxy resin on bamboo slices was investigated. And four surface modification treatments (heat treatment, alkali treatment, coupling treatment and acetylation treatment) were conducted on the bamboo slices. The regularities of mechanical properties of bamboo slices were illustrated by tensile tests and surface morphology analysis of modified bamboo slices, and the surface modification effects of different modification methods were characterized by Fourier-transform infrared spectroscopy (FT-IR). The research can provide scientific guidance for the utilization of bamboo in civil engineering and the epoxy resin in the anti-corrosion of natural plant

\section{MATERIAL AND METHODS}

According to the test methods for physical and mechanical properties of bamboo used in building (Chen et al. 2015), five-year-old Moso bamboos obtained from Enshi, Hubei Province in China were selected as objective materials. All pristine samples were selected from the outer portion of the bamboo and the location between $4-5 \mathrm{~m}$ measured from the bottom of the bamboo trunk, and were processed into slices with a uniform dimension of $200 \mathrm{~mm}(\mathrm{~L}) \times 5 \mathrm{~mm}(\mathrm{~W}) \times 1 \mathrm{~mm}(\mathrm{~T})$. The physical and mechanical parameters of Moso bamboo are listed in Tab. 1 according to relevant studies (Lakkad and Patel 1981, Jin et al. 2014).

Tab.1: Physical and mechanical parameters of Moso bamboo.

\begin{tabular}{|l|c|}
\hline \multicolumn{1}{|c|}{ Parameter } & Value range \\
\hline Density $\left(\mathrm{g} \cdot \mathrm{cm}^{-3}\right)$ & $0.6 \sim 1.1$ \\
\hline Tensile strength $(\mathrm{MPa})$ & $140 \sim 800$ \\
\hline Elastic modulus $(\mathrm{GPa})$ & $11 \sim 32$ \\
\hline Ultimate elongation $(\%)$ & $2.5 \sim 3.7$ \\
\hline Acid and alkali resistance & weak \\
\hline
\end{tabular}

\section{Corrosion test}

In order to study the influence of $\mathrm{pH}$ and corrosion time on the tensile properties of bamboo slices, as well as the anticorrosion property of epoxy resin on bamboo slices, solutions with different $\mathrm{pH}$ were prepared with a concentration of $35 \% \mathrm{HCl}$ reagent and a concentration of $5 \%$ $\mathrm{NaOH}$ reagent, and the coated samples were prepared by applying a layer of epoxy resin adhesive (E7730) evenly on the surface of the pristine sample followed by curing at room temperature for $24 \mathrm{~h}$. Correspondingly, one set of pristine samples and coated samples were marinated in the solutions with different $\mathrm{pH}$ in range $2-13$ for 15 days, and the other set of pristine samples and coated samples were impregnated in the solution of $\mathrm{pH} 4.0$ and $\mathrm{pH} 10.0$ for different time $(1,3,5,7,15,28$ days), respectively. The mass lose induced by corrosion were measured after soaked samples were washed with distilled water and followed by being stored under laboratory temperature $\left(20 \pm 2^{\circ} \mathrm{C}\right)$ and relative humidity $(65 \pm 15 \%)$ for 2 days. Afterwards, their tensile properties were measured.

\section{Surface modification treatment of bamboo slices}

The surface modification of bamboo slices consisted of following two physical methods: heat treatment and alkali treatment, and two chemical methods: silane coupling and acetylation coating: (1) Heat treated bamboo slices (HTBS). Bamboo slices were heated 
in a high- temperature test chamber $(\mathrm{H} / \mathrm{GDWJ}-500 \mathrm{~L})$ at $120^{\circ} \mathrm{C}$ for $4 \mathrm{~h}$. When the slices were cooled to room temperature, the mass loss rate was measured. (2) Alkali treated bamboo slices (ATBS). Bamboo slices were immersed in a solution of $5 \% \mathrm{NaOH}$ for $2 \mathrm{~h}$ at room temperature. After being taken out, they were washed repeatedly with dilute acid solution until the washing solution became neutral measured by $\mathrm{pH}$ meter, then they were dried in a high-temperature test chamber at $80^{\circ} \mathrm{C}$ for $4 \mathrm{~h}$. (3) Coupling agent treated bamboo slices (CTBS). Bamboo slices were immersed in mixture solutions (six part 95\% ethanol solution and four part $0.6 \%$ A-174 silane coupling agent) with $\mathrm{pH} 4.0$ adjusted by $50 \%$ acetic acid for $2 \mathrm{~h}$, then removed and dried in a high-temperature test chamber at $80^{\circ} \mathrm{C}$ for 4 h. (4) Acetylated bamboo slices (ALBS). Neutralize the alkali-treated bamboo slices with dilute acid, then immersed them in $50 \%$ acetic acid for $2 \mathrm{~h}$. After being taken out, they were washed with distilled water and dried in a high-temperature test chamber at $80^{\circ} \mathrm{C}$ for $4 \mathrm{~h}$.

After the modification, the surface morphology of all samples were observed by high-power microscope. Meanwhile, to characterize the influence of modification on chemical functional groups of the samples surface, Fourier transform infrared (FT-IR) spectra were measured by infrared spectroscopy (Thermo Nicolet 6700). Afterwards, applying a layer of epoxy resin (E7730) evenly on the surface of the modified samples. When the epoxy resin adhesive was completed cured by stored at room temperature for $24 \mathrm{~h}$, the ultimate tension of coated and uncoated samples was measured

\section{Tensile tests}

The preparation and test method of the tensile properties of bamboo slices was in accordance with the procedure described in testing methods for physical and mechanical properties of bamboo used in building (Chen et al. 2015). The laboratory Max Test universal testing machine (WDW-10E) was adopted for the tensile tests. A slice of polyethylene plastic with $10 \mathrm{~mm}$ length are glued by epoxy resin adhesive on each end of the testing sample to be fixed into the fixtures without splitting. When loading, the tensile direction of the testing machine should follow the longitudinal length direction of the bamboo slice. Only when the fracture location is at least $10 \mathrm{~mm}$ away from the fixture, can experimental results be judged as valid data. The test was terminated upon the sample was broken. The loading speed is uniformly $0.1 \mathrm{~mm} \cdot \mathrm{min}^{-1}$, and five effective replicates were conducted for each sample type

\section{RESULTS AND DISCUSSION}

\section{Tensile tests}

Effect of $\mathrm{pH}$ on ultimate tension of samples during laboratory

Fig. 1a shows that in the acidic environment, when UTBS were corroded in the solution with $\mathrm{pH} 6.0$ and $\mathrm{pH} 2.0$ for 15 days, respectively, the mass loss rate increased from $2.5 \%$ to $5.2 \%$, and the corresponding ultimate tension decreased from $0.525 \mathrm{kN}$ to $0.453 \mathrm{kN}$, which decreased by $24.1 \%$ and $34.5 \%$ respectively compared with that of uncorroded UTBS $(0.692 \mathrm{kN})$. Notably, because the $\mathrm{pH}$ of bamboo was between 5.1 and 6.6 (Lo et al. 2012), the bamboo slices corroded and the ultimate tension decreased by $0.163 \mathrm{kN}(23.6 \%)$ even under the neutral environment of $\mathrm{pH} 7.0$ for 15 days. In alkaline environment of $\mathrm{pH} 8.0$ and $\mathrm{pH} 13.0$, the mass loss rate increased from $1.34 \%$ to $5.3 \%$, and the corresponding ultimate tension decreased by $16.4 \%(0.114 \mathrm{kN})$ and $55.6 \%(0.385 \mathrm{kN})$ compared with that of uncorroded UTBS, respectively. However, as shown in Fig. 1b, when corroded for 15 days in both acidic and alkaline environments, the mass loss rate of the ERBS was negative and changed only slightly (the maximum was $-0.24 \%$ in $\mathrm{pH} 13$ ), 
which was attributed to the water absorption of epoxy resin adhesive (Popineau et al. 2005). Meanwhile, the ultimate tension of corroded ERBS only decreased slightly compared with that of ERBS without corrosion $(0.677 \mathrm{kN})$, and the maximum decrease was by $0.04 \%(0.027 \mathrm{kN})$ when corroded at $\mathrm{pH} 12.0$ for 15 days. It can be inferred that under the condition of constant corrosion time, the tensile properties of bamboo slices decrease with the increase of corrosion solution concentration, whereas epoxy resin can protect the tensile properties of bamboo slices from the influence of $\mathrm{pH}$
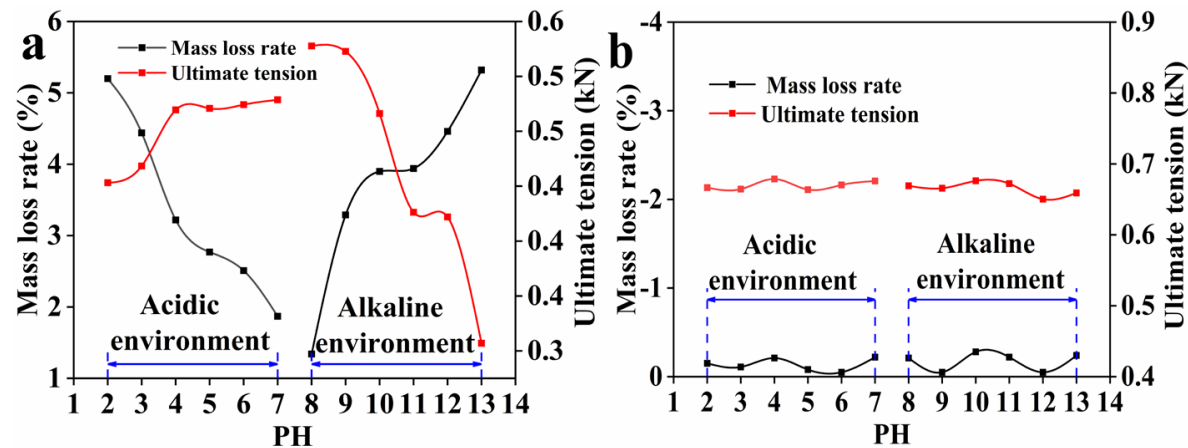

Fig. 1: Regularities of mass loss rate and ultimate tension of (a) pristine samples (UTBS) and (b) samples coated by epoxy resin adhesive (ERBS) under different $p H$.

Effect of corrosion time on ultimate tension of samples

As can be seen in Fig. 2a, with the increase of corrosion time, the mass loss rate of UTBS increases and the ultimate tension decreases under the condition of constant $\mathrm{pH}$. When UTBS were corroded in the solution with $\mathrm{pH} 4.0$ for 1 day and 28 days, respectively, the mass loss rate increased from $1.9 \%$ to $3.4 \%$, and the corresponding ultimate tension decreased from $0.678 \mathrm{kN}$ to $0.490 \mathrm{kN}$, which decreased by $2.0 \%$ and $29.2 \%$ respectively compared with that of uncorroded UTBS $(0.692 \mathrm{kN})$. The alkaline environment of $\mathrm{pH} 10.0$ had a greater impact on the ultimate tension of UTBS, which decreased by $9.0 \%(0.064 \mathrm{kN})$ and $38.6 \%(0.243 \mathrm{kN})$ when be corroded for 1 day and 28 days, respectively. As shown in Fig. 2b, the ultimate tension of corroded ERBS only decreased slightly compared with that of uncorroded ERBS $(0.677 \mathrm{kN})$, and the maximum decrease was by $0.08 \%(0.046 \mathrm{kN})$ when corroded at $\mathrm{pH} 4.0$ for 5 days, which means that corrosion time had slightly effect on the ultimate tension of ERBS.
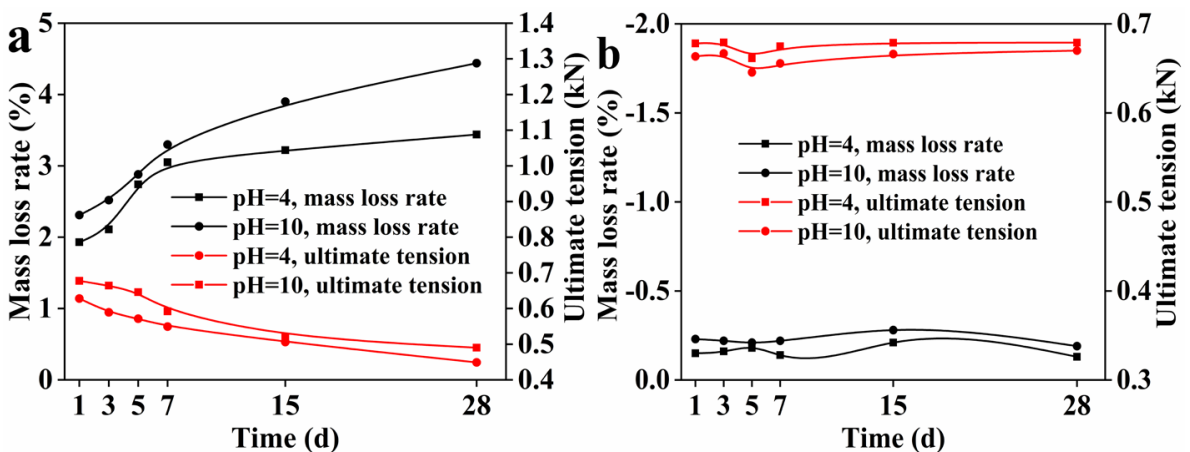

Fig. 2: Regularities of mass loss rate and ultimate tension of (a) UTBS and (b) ERBS under different corrosion time. 
The chemical composition of bamboo slices is mainly composed of cellulose, hemicellulose and lignin (Chen et al. 2011). Cellulose mainly determines the longitudinal tensile properties of plant cell walls, and the higher the cellulose content, the better the longitudinal tensile properties of cells ( $\mathrm{Li}$ and Shen 2011). Hemicellulose is closely related to cellulose and lignin in the cell wall and mainly acts as an adhesive (Vanholme et al. 2010). Lignin has the ability to increases the mechanical strength of cell walls, and to resist microbial erosion (Boerjan et al. 2003). The $\mathrm{HCl}$ and the $\mathrm{NaOH}$ are capable of degrade the cellulose, hemicellulose and lignin in the bamboo slices (Silverstein et al. 2007), which will further affect the tensile properties of bamboo slices. Consequently, with the increase of concentration of $\mathrm{HCl}$ and $\mathrm{NaOH}$ solution and corrosion time, the UTBS were prone to be affected by corrosion and tensile properties significantly decreased. However, the epoxy resin adhesive with good anti-corrosion performance, can work as a protective layer to protect the bamboo slices from corrosion induced by contacting with $\mathrm{HCl}$ and $\mathrm{NaOH}$ solution, so as to maintain rather than improve the excellent tensile mechanical properties of the bamboo slices. Therefore, the changes of $\mathrm{pH}$ and corrosion time have little effect in the tensile properties of ERBS.

\section{Tensile properties of surface modified bamboo slices}

Surface modification can cause different degrees of damage to the bamboo slices. Only when the improvement of the interface adhesion between the bamboo slices and the epoxy resin exceeds the reduction in the strength of the bamboo slices, the surface modification is meaningful (Liu et al. 2010).

Tab. 2: Ultimate tension of Moso bamboo slices treated with different surface modification.

\begin{tabular}{|l|c|c|}
\hline \multirow{2}{*}{ Samples of bamboo slices } & \multicolumn{2}{|c|}{ Ultimate tension (kN) } \\
\cline { 2 - 3 } & Uncoated & Coated \\
\hline UTBS & 0.692 & 0.677 \\
\hline HTBS & 0.538 & 0.805 \\
\hline ATBS & 0.456 & 0.789 \\
\hline CTBS & 0.369 & 0.693 \\
\hline ALBS & 0.402 & 0.847 \\
\hline
\end{tabular}

Tab. 2 shows that surface modification reduced the ultimate tension of bamboo slices, among which the maximal reduction is $0.323 \mathrm{kN}(46.6 \%)$ of CTBS, and the minimum reduction is $0.154 \mathrm{kN}(22.3 \%)$ of HTBS. Due to the small amount of water contained in the epoxy resin adhesive and the poor interface compatibility between the epoxy resin adhesive and the surface of bamboo slices (Zheng et al. 2018), the epoxy resin cannot improve the tensile properties of the bamboo slice when be coated on the surface of bamboo slice, and the ultimate tension of coated UTBS $(0.677 \mathrm{kN})$ is $0.015 \mathrm{kN}(1.4 \%)$ less than that of uncoated UTBS $(0.692 \mathrm{kN})$. Moreover, compared with uncoated modified samples, the ultimate tension of coated modified samples has been increased to different degrees. The maximal increase is $0.445 \mathrm{kN}(110.7 \%)$ of ALBS, the minimum increase is $0.267 \mathrm{kN}(38.6 \%)$ of HTBS. And compared with coated UTBS, the maximal increase of ultimate tension is by $0.170 \mathrm{kN}(25.1 \%)$ of ALBS. Owing to the damage of coupling agent treatment to the tensile properties of bamboo slices, the minimum increase of ultimate tension is only by $0.016 \mathrm{kN}(2.3 \%)$ of CTBS. Which indicates that the four modifications improved the interfacial compatibility between the surface of bamboo slices and the epoxy resin adhesive, the treatment of coupling agent in terms ) of improving the tensile properties of bamboo slices is not obvious, and the treatment of acetylation is the most effective method among them. 


\section{Surface morphology analysis of bamboo slices}

The surface of UTBS (Fig. 3a) is relatively smooth and flat, with a few impurity particles. In comparison, the surface of the physically modified bamboo slices (HTBS and ATBS) has become rough and uneven to varying degrees, which can improve the interfacial combination between the surface of bamboo slices and the epoxy resin adhesive. It can be clearly observed that the surface of HTBS (Fig. 3b) is rougher, with many uneven potholes and the color becomes darker. This is because the heat treatment removed the impurities on the surface of bamboo slices, and made part of cellulose and hemicellulose in the bamboo thermal degradation and carbonization (Kartal et al. 2008). Besides, the surface of ATBS (Fig. 3c) becomes rough which can be attributed to the removal of impurities and the dissolution of some lignin and hemicellulose in bamboo slices by alkali treatment (Zhang et al. 1994). The surfaces of chemically modified CTBS (Fig. 3d) and ALBS (Fig. 3e) do not become evidently rough, but the materials become relatively soft. And the improvement of interfacial compatibility between the surface of bamboo slices and the epoxy resin adhesive, can be reasonably explained by the fact that silane coupling agent can reduce the content of hydroxyl group, and acetyl group can replace the hydroxyl group on the cell wall of the bamboo slices, as shown in Fig. 4. Both chemical modifications reduced the water absorption of bamboo slices and made them malleable.

The interface layer which exists between epoxy resin and the bamboo slice plays a decisive role in the mechanical properties of the epoxy resin-coated bamboo slice (Rong et al. 2001). All the four modification methods can change the surface morphology of the bamboo slices, and improve the interfacial combination between the surface of bamboo slices and the epoxy resin adhesive, which confirms the conclusion that the ultimate tension of coated samples can be enhanced by modification before the epoxy resin is coated
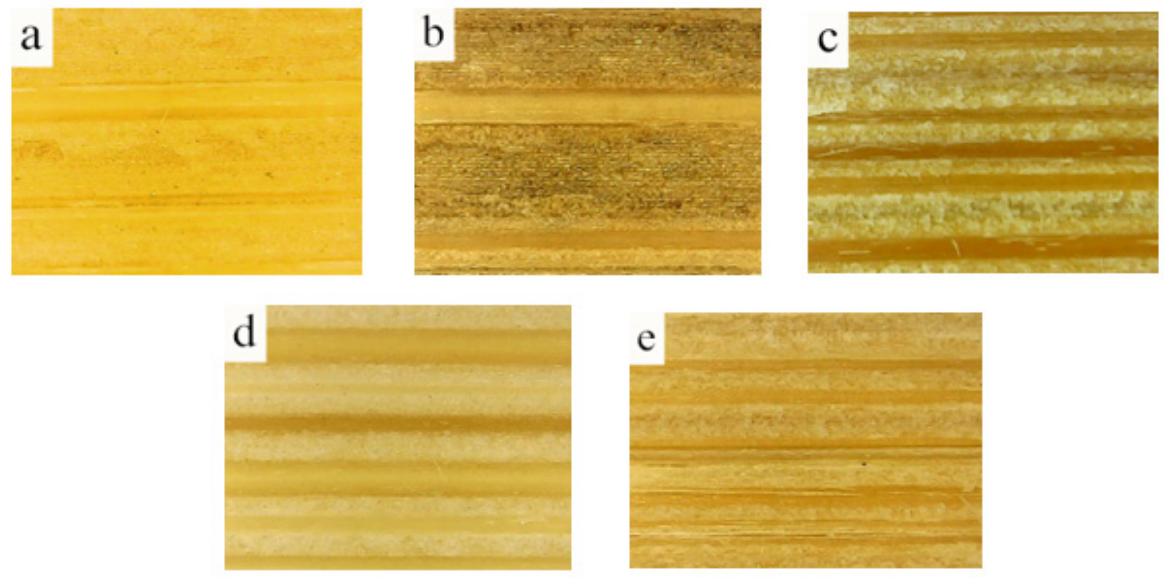

Fig. 3: Surface micrographs of (a) UTBS, (b) HTBS, (c) ATBS, (d) CTBS and (e) ALBS.

\section{Infrared spectroscopic analysis}

FT-IR can be used to qualitatively analyze the change of surface functional groups of bamboo slices caused by modification. As can be seen in Fig. 4, due to the dissolution of hemicellulose in bamboo slices after acetylation treatment, the carbonyl functional group $(\mathrm{C}=\mathrm{O})$ at $1720 \mathrm{~cm}^{-1}$ of ALBS corresponding to hemicellulose disappeared. Which confirmed the conclusion that the treatment of acetylation is the most effective method for improving the interfacial compatibility between the surface of bamboo slices and the epoxy resin adhesive. Besides, the FT-IR of the other three modified bamboo slices are almost the same with the untreated bamboo slice 
(UTBS), which can be attributed to the fact that the physical modification method does not cause chemical changes on the surface of bamboo slices. Although silane coupling agent can reduce the content of hydroxyl groups on the surface of bamboo fibers, the effect is not obvious.

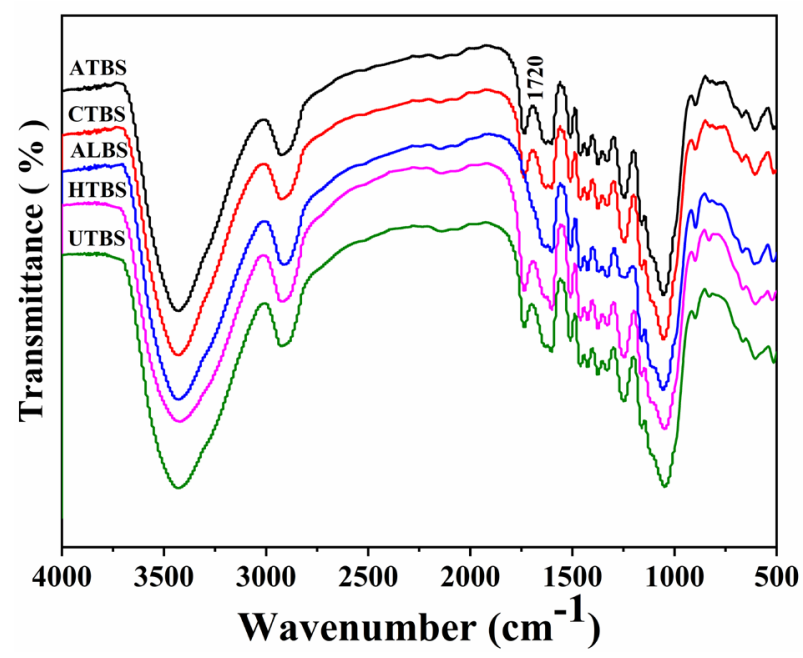

Fig. 4: FT-IR spectra of bamboo slices treated by different modifications.

\section{CONCLUSIONS}

(1) As an elastic material, Moso Bamboo has poor corrosion resistance, the acid and alkali environment will cause corrosion to bamboo slices and affect their tensile properties. Moreover, with the increase of acid and alkali solution concentration and marinating time, the ultimate tension of bamboo slices gradually decreases. The maximum reduction is $0.385 \mathrm{kN}(55.6 \%)$ when be corroded in solution with $\mathrm{pH} 13.0$ for 15 days, and $0.243 \mathrm{kN}(38.6 \%)$ when be corroded in solution with $\mathrm{pH} 10.0$ for 28 days. Therefore, anticorrosive treatment or other protective measures can be taken to protect the tensile properties and extend the service life of Moso bamboo. (2) Coating the surface of bamboo slices with epoxy resin adhesive can protect them from corrosion by acid and alkali environment. However, due to the poor interfacial compatibility between the surface of bamboo slice and the epoxy resin adhesive, the epoxy resin adhesive can only maintain but not improve the tensile mechanical properties of bamboo. Reasonable surface modification can be taken to improve their interfacial compatibility. (3) Surface modification will reduce the ultimate tension of bamboo slices. Among which the maximal reduction is 0.323 $\mathrm{kN}(46.6 \%)$ of bamboo slices treated by coupling agent, and the minimum reduction is $0.154 \mathrm{kN}$ (22.3\%) of bamboo slices treated by heating. The surface morphology indicates that modification can make the surface of bamboo slices become rough or the material become relatively soft, which can improve the interfacial compatibility between the surface of bamboo slice and the epoxy resin adhesive. Compared with the unmodified coated bamboo slice, the treatment of coupling agent in terms of improving the tensile properties of bamboo slices is not obvious, only increases by $0.016 \mathrm{kN}(2.3 \%)$, and the treatment of acetylation is the most effective modification by reacting with the carbonyl group, which ultimate tension has been increased by $25.1 \%$ $(0.170 \mathrm{kN})$. 


\section{ACKNOWLEDGMENT}

The authors are very grateful that this research was financially supported by grants from National Key R\&D Program of China (No. 2016YFC0502208), National Natural Science Foundation of China (NSFC) (No. 51678223), Hubei Provincial Education Department Key Project (No. D20171402), and Green Industrial Project of Hubei University of Technology (No.YXQN2017001).

\section{REFERENCES}

1. Ahmad, M., Kamke, F., 2005: Analysis of Calcutta bamboo for structural composite materials: physical and mechanical properties. Wood Science and Technology 39(6): 448-459.

2. Antov, P., Savov, V., Neykov, N., 2020: Sustainable bio-based adhesives for eco-friendly wood composites. A review. Wood Research 65(1): 51-62.

3. Bledzki, A.K., Reihmane, S., Gassan, J., 1996: Properties and modification methods for vegetable fibers for natural fiber composites. Journal of Applied Polymer Science 59(8): 1329-1336.

4. Boerjan, W., Ralph, J., Baucher, M., 2003: Lignin biosynthesis. Annual Review of Plant Biology 54(1): 519-546.

5. Chen, H., Cheng, H.T., Wang, G., Yu, Z.X., Shi, S.Q. 2015: Tensile properties of bamboo in different sizes. Journal of Wood Science 61(6): 552-561.

6. Chen, W.S., Yu, H.P., Liu, Y.X., Hai, Y.F., Zhang, M.X., Chen, P., 2011: Isolation and characterization of cellulose nanofibers from four plant cellulose fibers using a chemicalultrasonic process. Cellulose 18(2): 433-442.

7. Ghestem, M., Sidle, R.C., Stokes, A., 2011: The influence of plant root systems on subsurface flow: implications for slope stability. Bioscience 61(11): 869-879.

8. Hegde, A., Sitharam, T.G., 2015: Use of bamboo in soft-ground engineering and its performance comparison with geosynthetics: experimental studies. Journal of Materials in Civil Engineering 27(9): 04014256.

9. Hsu, T.C., Guo, G.L., Chen, W.H., Hwang, W.S., 2010: Effect of dilute acid pretreatment of rice straw on structural properties and enzymatic hydrolysis. Bioresource Technology 101(13): 4907-4913.

10. Jin, C., Li, J., Han, S., Wang, J., Sun, Q., 2014: A durable, superhydrophobic, superoleophobic and corrosion-resistant coating with rose-like $\mathrm{ZnO}$ nanoflowers on a bamboo surface. Applied Surface Science 320: 322-327.

11. Kartal, S.N., Hwang, W.J., Imamura, Y.J., 2008: Combined effect of boron compounds and heat treatments on wood properties: Chemical and strength properties of wood. Journal of Materials Processing Technology 198(1-3): 234-240.

12. Khalil, H.P.S.A., Bhat, I.U.H., Jawaid, M., Zaidon, A., Hermawan, D., Hadid, Y.S., 2012: Bamboo fibre reinforced biocomposites: a review. Materials and Design 42: 353-368.

13. Lakkad, S., Patel, J., 1981: Mechanical properties of bamboo, a natural composite. Fibre Science and Technology 14(4): 319-322.

14. Li, H., Shen, S., 2011: The mechanical properties of bamboo and vascular bundles. Journal of Materials Research 26(21): 2749-2756.

15. Li, M., Chai, S.X., Zhang, H.Y., Du, H.P., Wei, L., 2012: Feasibility of saline soil 
reinforced with treated wheat straw and lime. Soils and Foundations 52(2): 228-238.

16. Liu, T.M., Zheng, Y.S., Hu, J., 2010: Surface modification of aramid fibers with new chemical method for improving interfacial bonding strength with epoxy resin. Journal of Applied Polymer Science 118(5): 2541-2552.

17. Lo, S.F., Wang, S.Y., Tsai, M.J., Lin, L.D., 2012: Adsorption capacity and removal efficiency of heavy metal ions by Moso and Ma bamboo activated carbons. Chemical Engineering Research and Design 90(9): 1397-1406.

18. Luft, J.H., 1961: Improvements in epoxy resin embedding methods. Journal of Cell Biology 9(2): 409-414.

19. Luo, H., Yue, L., Wang, N., Zhang, H., Lu, X., 2014: Manufacture of binderless fiberboard made from bamboo processing residues by steam explosion pretreatment. Wood research 59(5): 861-870.

20. Ma, Q. Yang, Y., Xiao, H., Xing, W., 2018: Studying shear performance of flax fiberreinforced clay by triaxial test. Advances in Civil Engineering 2018: 1-8.

21. Ma'ruf, M.F., 2012: Shear strength of Apus bamboo root reinforced soil. Ecological Engineering 41: 84-86.

22. McIvor, I.R., Douglas, G.B., Hurst, S.E., Hussain, Z., Foote, A.G., 2008: Structural root growth of young Veronese poplars on erodible slopes in the southern North Island, New Zealand. Agroforestry Systems 72(1): 75-86.

23. Popineau, S., Rondeau-Mouro, C., Sulpice-Gaillet, C., Shanahan, M.E., 2005: Free/bound water absorption in an epoxy adhesive. Polymer 46(24): 10733-10740.

24. Qin, D., Ren, H., Zhang, L., Li, Z., 2015: Enhancing enzymatic digestibility of bamboo by fungal pretreatment. Wood Research 60(1): 25-32.

25. Rong, M.Z., Zhang, M.Q., Liu, Y., Yang, G.C., Zeng, H.M., 2001: The effect of fiber treatment on the mechanical properties of unidirectional sisal-reinforced epoxy composites. Composites Science and Technology 61(10): 1437-1447

26. Shafizadeh, S., Kavanagh, J.A., 2005: Pathogenicity of Phytophthora spp. species and Pythium undulatum isolated from Abies procera Christmas trees in Ireland. Forest Pathology 35(6): $444-450$.

27. Shinoda, M., Bathurst, R.J., 2004: Lateral and axial deformation of PP, HDPE and PET geogrids under tensile load. Geotextiles and Geomembranes 22(4): 205-222.

28. Silverstein, R.A., Chen, Y., Sharma Shivappa, R.R., Boyette, M.D., Osborne, J., 2007: A comparison of chemical pretreatment methods for improving saccharification of cotton stalks. Bioresource Technology 98(16): 3000-3011.

29. Subaida, E., Chandrakaran, S., Sankar, N., 2008: Experimental investigations on tensile and pullout behaviour of woven coir geotextiles. Geotextiles and Geomembranes 26(5): 384-392.

30. Trujillo, E., Moesen, M., Osorio, L., Vuure, A.W.V., Ivens, J., Verpoest, I., 2014: Bamboo fibres for reinforcement in composite materials: strength Weibull analysis. Composites Part A: Applied Science and Manufacturing 61: 115-125.

31. Vanholme, R., Demedts, B., Morreel, K., Ralph, J., Boerjan, W., 2010: Lignin biosynthesis and structure. Plant Physiology 153(3): 895-905.

32. Wesseloo, J., Visser, A.T., Rust, E., 2004: A mathematical model for the strain-rate dependent stress-strain response of HDPE geomembranes. Geotextiles and Geomembranes 22(4): 273-295.

33. Yan, W., Zhou, J., Zhang, B., Fu, W., Chen, Z., 2017: Development design and mechanical properties of arc bamboo. Wood Research 62(3): 365-372. 
34. Yang, W.J., Neoh, K.G., Kang, E.T., Teo, S.L.M., Rittschof, D., 2014: Polymer brush coatings for combating marine biofouling. Progress in Polymer Science 39(5): 1017-1042.

35. Yun, H., Li, K., Tu, D., Hu, C., South, G.C., 2016: Effect of heat treatment on bamboo fiber morphology crystallinity and mechanical properties. Wood Research 61(2): 227-233

36. Zhang, M.Q. Zhu, S.P., Zeng, H.M., Lu, Y., 1994: A biomaterial based carbon fiber. Die Angewandte Makromolekulare Chemie: Applied Macromolecular Chemistry and Physics 222(1): 147-163.

37. Zhao, X., Tu, D., Chen, C., Zhou, Q., 2019: Prediction of the mechanical properties of thermally-modified rubber wood on the basic of its surface characteristic. Wood Research 64(1): 25-34.

38. Zheng, K.K., Gao, C.H., He, F.S., Lin, Y.X., Liu, M., Lin, J., 2018: Study on the interfacial functionary mechanism of rare-earth-solution-modified bamboo-fiber-reinforced resin matrix composites. Materials 11(7): 1190-1205. 
Qiang Ma, Zhao Liu, Henglin Xiao, Zhi Chen*

Hubei University Of Technology

School Of Civil Engineering And Architecture

WUHAN 430068

China

*Corresponding author: chenzhi1988420@126.com 